\title{
Considerações sobre a análise de Grundgestalt aplicada à música popular
}

\author{
Carlos de Lemos Almada (UFRJ, Rio de Janeiro, RJ) \\ calmada@globo.com
}

\begin{abstract}
Resumo: Este artigo discute a adequação do emprego de ferramentas analíticas associadas à teoria da Grundgestalt de Schoenberg para o exame de relações estruturais em peças de música popular. Após a apresentação dos conceitos básicos, são examinadas algumas conclusões presentes em um artigo pioneiro de GREEN (2008) sobre o tratamento motívico de Duke Ellington. Em seguida, as canções Chovendo na Roseira, de Tom Jobim e Something, de George Harrison são analisadas com o uso de metodologia especifica desenvolvida pela pesquisa à qual está associado este estudo. Os resultados obtidos sugerem que, embora limitada a condições especiais e com as devidas adaptações, é perfeitamente possível a aplicação de análise derivativa em peças de música popular.
\end{abstract}

Palavras-chave: Grundgestalt e variação progressiva; música popular; análise derivativa.

\section{Issues on the Grundgestalt analysis applied to popular music}

Abstract: This paper deals the suitability of the use of analytical tools associated with Schoenberg's theory of Grundgestalt for the examination of structural relationships in pieces of popular music. Following the presentation of basic concepts, some of the conclusions presented in a pioneering paper by GREEN (2008), on Duke Ellington's motivic treatment are examined. Afterward, the songs Chovendo na Roseira, by Tom Jobim, and Something, by George Harririson are analyzed with specific methodology developed in the research which this study is inserted. The results suggest that, although limited to special conditions and requiring appropriate adaptations, it is possible to apply the derivative analysis to pieces of popular music.

Keywords: Grundgestalt and developing variation; popular music; derivative analysis.

\section{1- Introdução}

Este trabalho apresenta-se como a confluência de dois projetos de pesquisa em andamento: o primeiro deles dedicado a um estudo abrangente sobre os princípios de Grundgestalt e variação progressiva, sendo o segundo voltado para a aplicação de metodologias analíticas sistemáticas (especificamente ligadas ao exame estrutural) em peças de música popular. Ambas as pesquisas têm resultado em vários desdobramentos, ${ }^{1}$ entre os quais se encontra o presente estudo, que essencialmente examina questões relacionadas ao processo criativo envolvido no desenvolvimento motívico-temático a partir de uma ideia musical básica dentro de obras de música popular. Tomando como ponto de partida um artigo pioneiro sobre o assunto (GREEN, 2008), que sustenta a existência de processos derivativos na composição de algumas peças de Duke Ellington, e discutindo brevemente o grau de controle com que tais processos podem ser manipulados por compositores (populares ou não), este estudo finaliza com duas análises de Grundgestalt das canções Chovendo na Roseira, de Tom Jobim e Something, de George Harrison.

\section{2 - Conceituação básica}

Os princípios Grundgestalt e variação progressiva (originalmente developing variation) representam talvez a principal das contribuições teóricas de Arnold Schoenberg no universo da composição musical. Ambos os conceitos são centrais para a compreensão dos processos construtivos empregados na produção de sua própria obra, bem como na de seus principais seguidores (notadamente, Alban Berg).

Abrangendo todas as fases criativas de Schoenberg (tonal, atonal e serial), a concepção organicista, baseada na extração de todo (ou quase todo) material construtivo de uma peça a partir de sua configuração motívica inicial (Grundgestalt), decorrente da antevisão da criação completa (a Ideia - Die Idee), é sem dúvida o denominador comum que correlaciona seu pensamento teórico e sua música. $^{2}$ A teoria da Grundgestalt foi deduzida pelo compositor a partir de minuciosas e criteriosas análises das obras daqueles que ele considerava como seus grandes mestres: Bach, Mozart, Haydn, Beethoven e, especialmente, Brahms. ${ }^{3}$ 
Como uma semente, uma dada Grundgestalt teria ao menos no caso idealizado - o potencial de gerar todo o material necessário para a construção de uma peça, desenvolvendo-se como uma entidade orgânica. As inúmeras formas intermediárias (incluindo aquelas marcadamente contrastantes em relação ao elemento original) brotariam, por assim dizer, dessa semente, por intermédio de procedimentos de variação progressiva, isto é, variação sobre variação, considerando quaisquer domínios musicais possiveis (em especial, contornos intervalares e rítmicos, configurações métricas, contextos harmônicos, mas também timbres, padrões de articulação etc.).

\section{3 - Grundgestalt e variação progressiva em música popular}

Diante de tais circunstâncias, é perfeitamente compreensivel que, por exigir para seus adequados desdobramentos grandes extensões e uma imprescindivel complexidade estrutural, a presença do binômio Grundgestalt/variação progressiva não seria favorecida em contextos de música popular, ao menos de acordo com os modelos normalmente estudados. Com raras exceções, peças populares, independentemente dos gêneros envolvidos, possuem estruturas relativamente simples, dispostas em poucas camadas hierárquicas, além de curta duração, inviabilizando construções orgânicas a partir de desenvolvimento gradual. Contudo, há evidências que suportam a hipótese de que, embora bastante raros e limitados em abrangência, processos composicionais baseados em Grungestalt são também possíveis na música popular.

Em um artigo pioneiro nesse campo, Edward GREEN (2008) investiga a possibilidade de que algumas das peças de Duke Ellington - mais especificamente The Mooche (1928), Ko-Ko (1940) e The Far East Suite (1963-66) tenham sido compostas a partir do desenvolvimento de ideias motívicas básicas (essencialmente associadas a contornos intervalares), das quais foram extraídas relações em vários níveis de significação estrutural. Outro ponto importante destacado por Green em seu texto é a hipótese de que Ellington tenha conseguido desenvolver sua notória maestria no trato motívico a partir de estudos informais com Will Marion Cook (1869-1944), compositor americano com atuação no teatro musical, porém com uma sólida formação na tradição europeia. Denominado por seus contemporâneos "o Bach negro", Cook é reconhecido por sua predileção por um tratamento motívico-temático bastante sofisticado e intensamente baseado em processos de desenvolvimento através da variação de ideias musicais básicas. Como o autor conclui em seu artigo, as elaborações de Ellington são claramente resultado de um processo cuidadoso e calculado, sejam elas originadas da composição "em papel", ou através de criações improvisadas (muitas vezes coletivamente) nos estúdio de gravação (GREEN, 2008, p.245). Um outro grande compositor americano de música popular,
George Gershwin, também é conhecido pela maestria com que realizava o trabalho motívico, desenvolvida muito provavelmente a partir de seus estudos com Joseph Schillinger, como revelam algumas análises detalhadas de peças selecionadas do compositor (GILBERT, 1984).

A existência dessa hipótese, ou seja, de que as "heranças" recebidas por Ellington e Gershwin de seus respectivos mestres, Cook e Schillinger, seriam responsáveis (ao menos em parte) por suas habilidades na arte da variação, aplicadas - é relevante acrescentar - de maneira consciente e calculada levanta algumas questões importantes: até que ponto um compositor controla efetivamente a criação derivativa? Como faz suas escolhas diante de um número de alternativas virtualmente infinito (ou, ao menos, imponderável)? É possivel que existam peças nas quais redes complexas de derivação se estabeleçam sem o "conhecimento" consciente do compositor?

Ainda que sejam questões extremamente instigantes, não é do escopo deste artigo a busca por suas respostas, o que estenderia a investigação aos campos da psicologia e da cognição musicais (e certamente envolveria estudos empíricos específicos). Pretende-se aqui tão-somente discuti-las a partir de alguns exemplos. Certamente, os casos de Ellington e Gershwin são bem particulares e relativamente raros no universo da música popular. Não por acaso - e isto é sintomático - atribui-se a origem de suas concepções derivativas a conhecimentos (formais ou não, direta ou indiretamente, isso é irrelevante) oriundos da tradição musical erudita. De qualquer maneira, ainda que se evidencie que esses dois compositores tenham controlado os processos derivativos em suas peças, sempre seria possivel discutir sobre os níveis profundidade e abrangência com que um controle dessa natureza pode ser exercido. Informalmente, sabe-se da existência de casos nos quais um compositor, por assim dizer, "perde" o domínio sobre uma obra, que procede (ao menos aparentemente) de maneira autônoma, apresentando relações profundas de coerência e de parentesco entre ideias musicais que, não raras vezes, são constatadas apenas a partir de análises especificas. Em um exemplo famoso, SCHOENBERG (1984, p.222-3) revela a grande surpresa que teve ao perceber, vários anos após sua composição, conexões até então insuspeitadas entre dois temas de funções e naturezas contrastantes dentro da seção inicial de sua Primeira Sinfonia de Câmara op.9. Ou seja, uma espécie de trabalho subconsciente que Schoenberg atribuiu ao que denomina seu senso de forma (extremamente apurado, diga-se). Além desse caso provavelmente único (uma constatação feita pelo próprio compositor), as análises de Grundgestalt realizadas sobre obras do repertório erudito (de estilos, épocas e autores distintos) costumam revelar associações semelhantes, muitas vezes surpreendentes e quase que certamente não planejadas pelos respectivos compositores. Pois parece ser justamente este o caso sugerido pelas análises que se seguem. 


\section{4 - Duas análises de Grundgestalt em música popular}

A primeira peça a ser abordada é a canção Chovendo na Roseira, de Tom Jobim. Entre as conclusões de um trabalho recente a respeito de sua estrutura (ALMADA, 2010), observou-se a proeminência do intervalo de quarta justa descendente como elemento construtivo, projetando-se em diversos estratos de organização. $\mathrm{Na}$ presente abordagem, a abstração do motivo inicial (que, metaforicamente, pode ser associado à queda dos pingos de chuva) desponta como uma perfeita (e relativamente simples) Grundgestalt para a canção, que é apresentada no Ex.1, ao lado de duas de suas derivações. ${ }^{4}$

Como se percebe, a dedução da Grundgestalt a partir do que é fornecido pela superfície musical (ou "plano concreto") acontece no que poderia ser denominado "plano abstrato", no qual duas formas derivadas básicas são também produzidas, a partir de operações de inversão (forma b) e de mudança de registro do elemento inicial, a nota Lá (forma c). ${ }^{5}$

A análise derivativa de Chovendo na Roseira mostra de maneira bem clara que é possível considerar apenas essas três formas básicas como elementos-chave na estruturação de alturas (ver Ex.2).

A partir dessa perspectiva, é possível mesmo encontrar uma explicação razoável para o enigmático (em relação aos eventos superficiais) acorde de F\# 7(b9) que antecede 0 início da seção B. 0 que aparenta ser uma resolução evadida de um dominante secundário pode ser reinterpretado, a partir das relações derivadas da Grundgestalt, como um movimento convencional dominante-tônica provisória (em relação a Si maior), intercalado por um trecho episódico (a seção contrastante B). Uma nova redução,
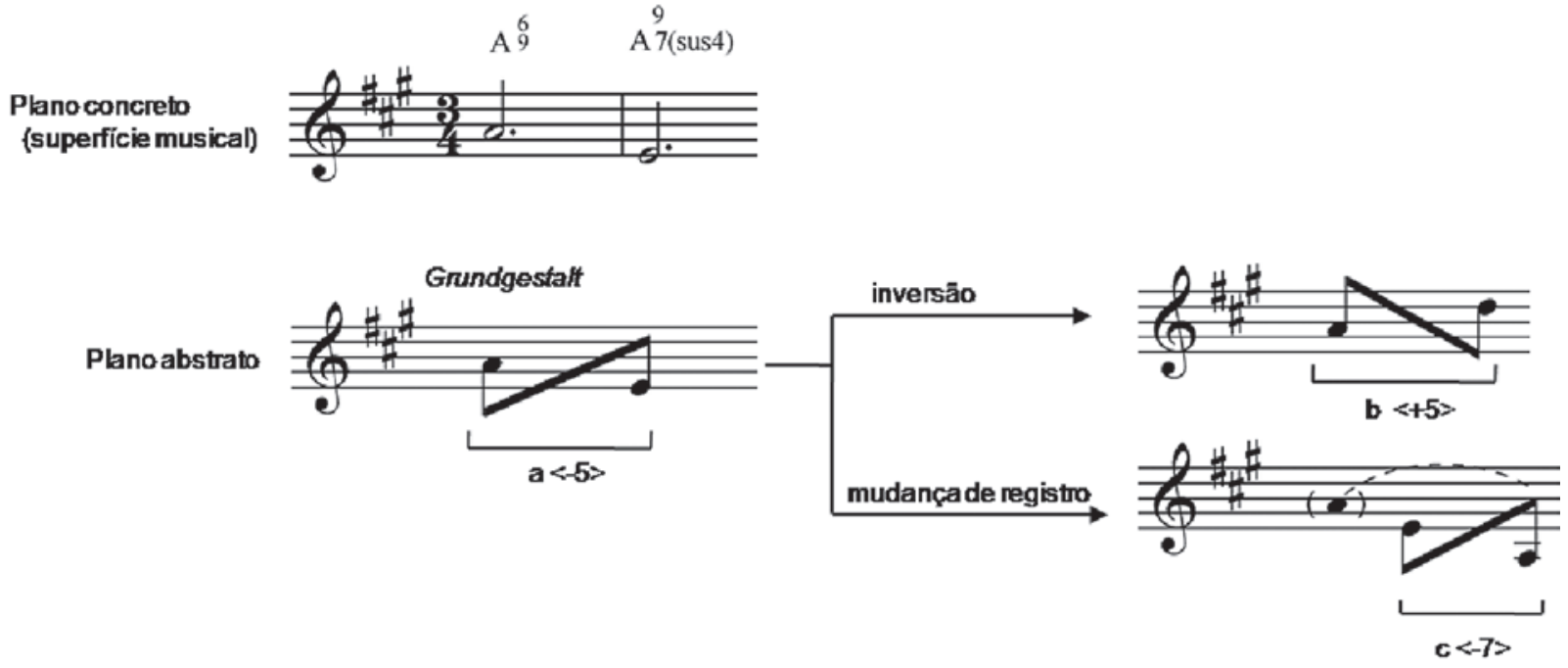

Ex.1 - Chovendo na Roseira - abstração do motivo inicial, gerando a Grundgestalt da peça (a) e duas variantes (b e c)

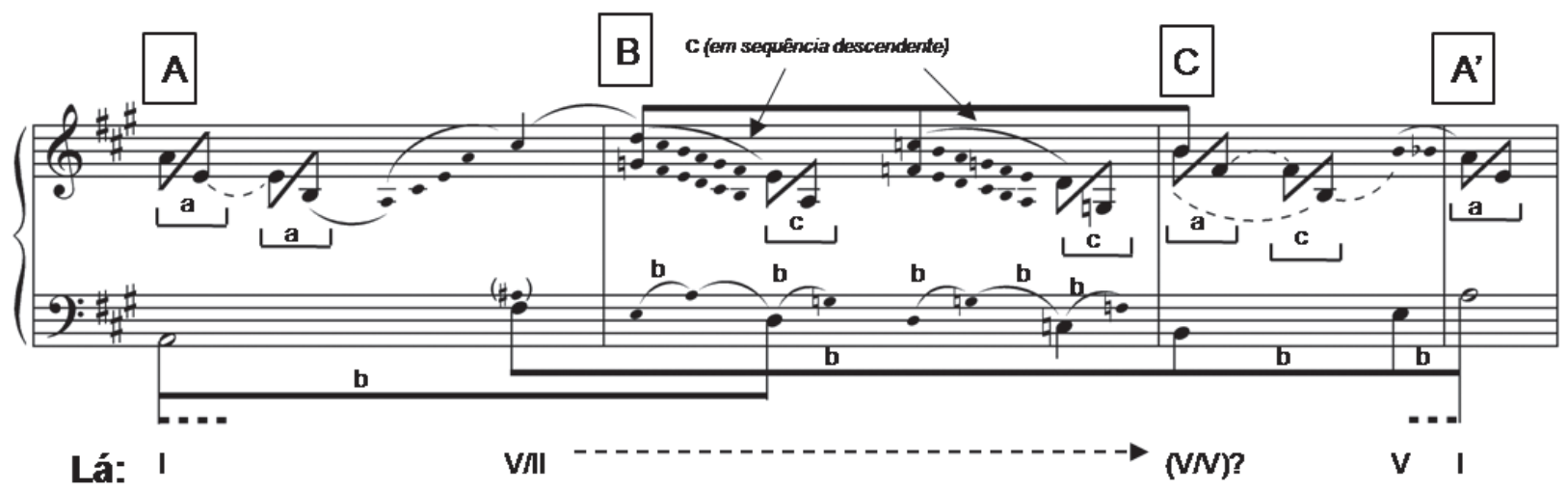

Ex.2 - Chovendo na Roseira - análise derivativa (primeiro nível intermediário) 
suprimindo os eventos subordinados da seção $B$, torna tal interpretação mais evidente (Ex.3).

Esta análise também permite observar que as abstrações $(a, b, c)$ apresentam-se em posições hierárquicas e funções distintas, associando-se à própria narrativa formal: o elemento a (Grundgestalt) prevalece nas seções de maior importância $\left(A, C\right.$ e $\left.A^{\prime}\right)$, enquanto que o trecho contrastante $(B)$, estruturalmente menos relevante, mostra-se apropriadamente como o território de atuação da forma derivada $c_{1}$ à maneira de um breve desenvolvimento tradicional. Ao mesmo tempo, 0 elemento $b$ exerce uma função claramente harmônica, conectando as fundamentais dos acordes de destaque na peça: F\#7(b9)-B7(sus4)-E7(b9)-A69.

Beirando o mais puro acaso, mas nem por isso menos surpreendente, é possível perceber que com a combinação das alturas-chave (Lá-Mi-Dó\#-Fá\# e Si), reveladas pela redução analítica do Ex.3, pode ser formado o acorde principal da tonalidade de referência (A69), na disposição elaborada por Jobim (Ex.4).

A segunda análise focaliza a canção Something, de George Harrison. Neste caso, a Grundgestalt origina-se no bem conhecido riff de guitarra que precede a entrada do canto (Ex.5). ${ }^{6}$

Como no caso anterior, a Grundgestalt (a) está baseada em um intervalo melódico (desta vez, de terça menor ascendente). No entanto, posiciona-se em um nível intermediário entre a superfície e a configuração intervalar que lhe dá suporte (b), manifestando-se como um fragmento cromático ascendente (ou seja, subdivide a terça menor em três passos de semitom). A inversão (ou retrogradação) de a resulta na forma abstrata $c_{1}$ que abrange, implicitamente, não apenas o intervalo correspondente de terça menor descendente, como uma

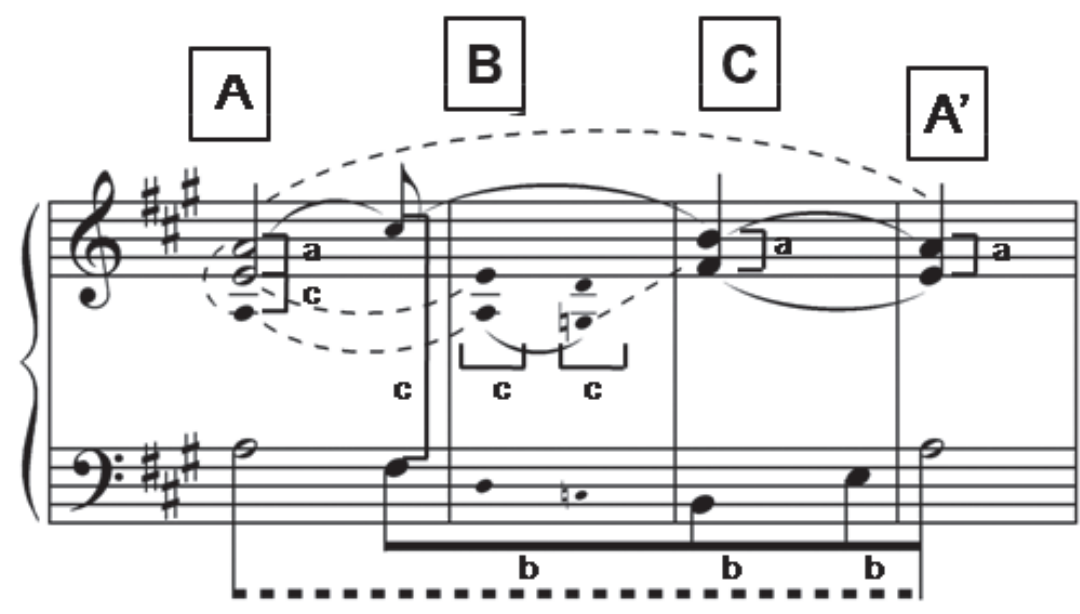

Ex.3 - Chovendo na Roseira - análise derivativa (segundo nível intermediário)

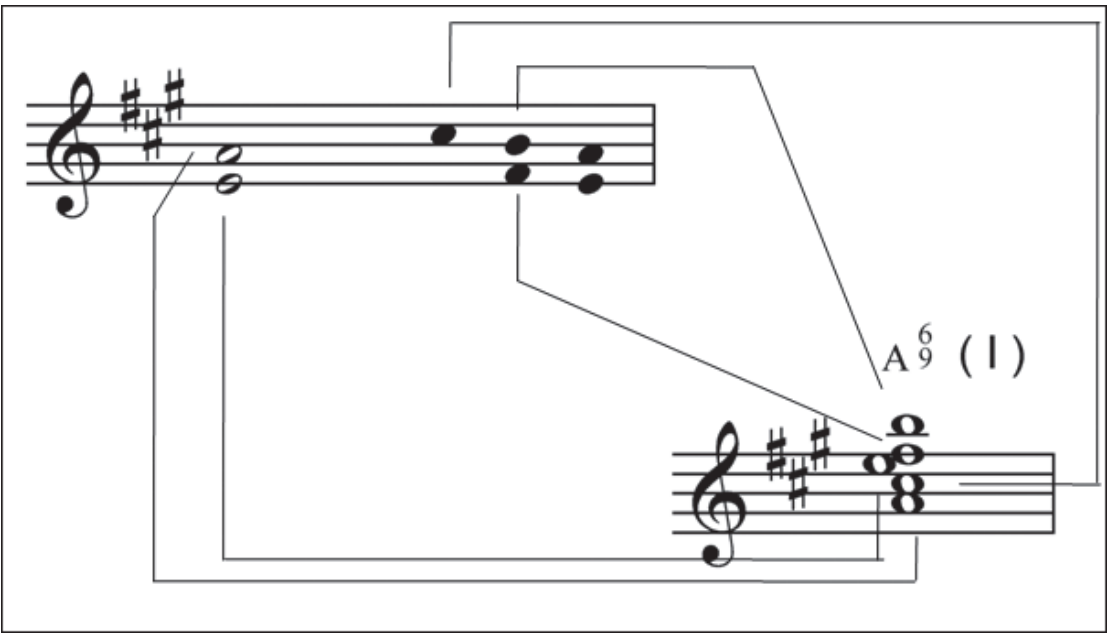

Ex.4 - Chovendo na Roseira - formação do acorde de I grau, a partir das alturas-chave (Lá-Mi-Dó\#-Fá\# e Si) 


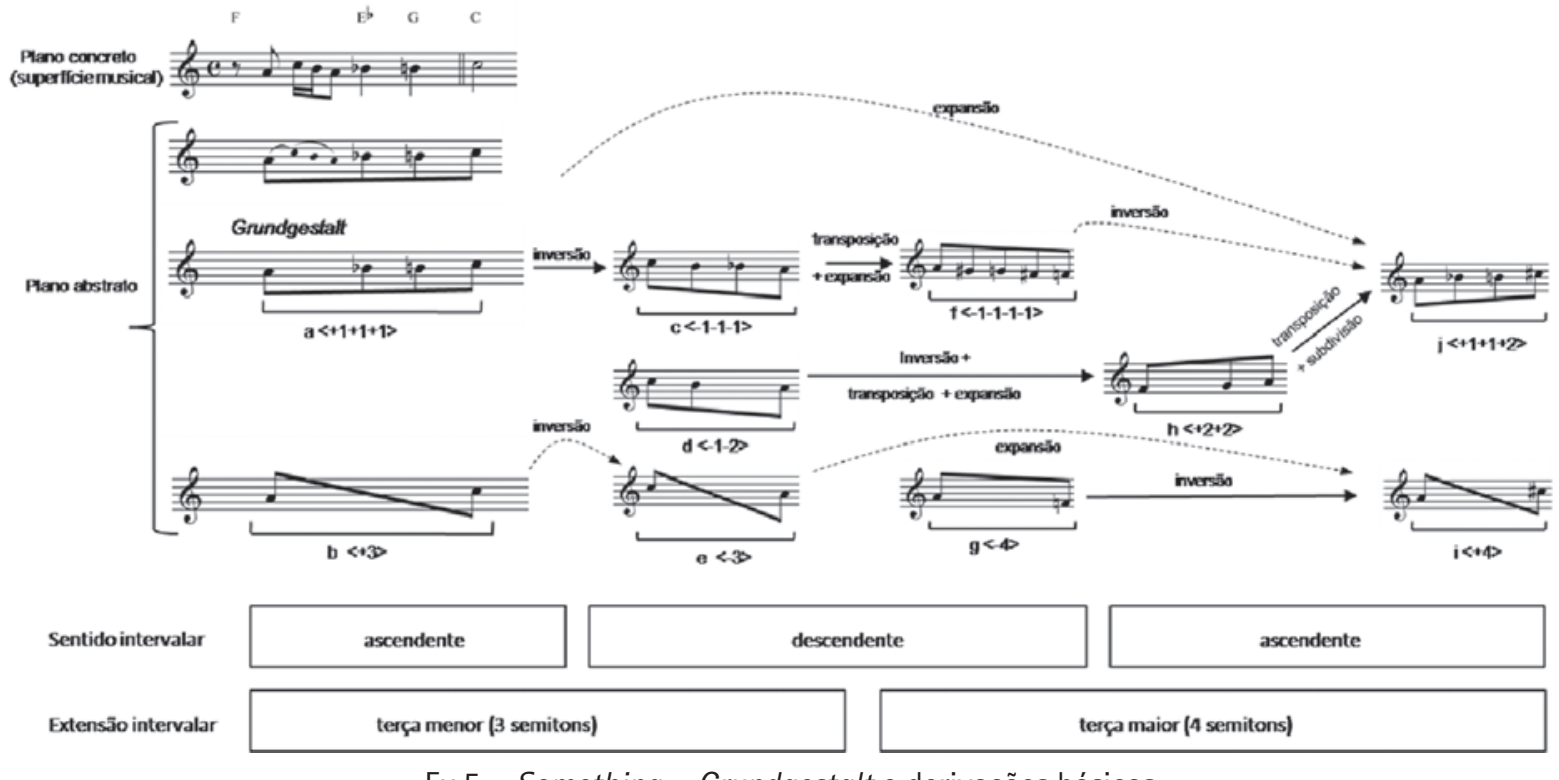

Ex.5 - Something - Grundgestalt e derivações básicas

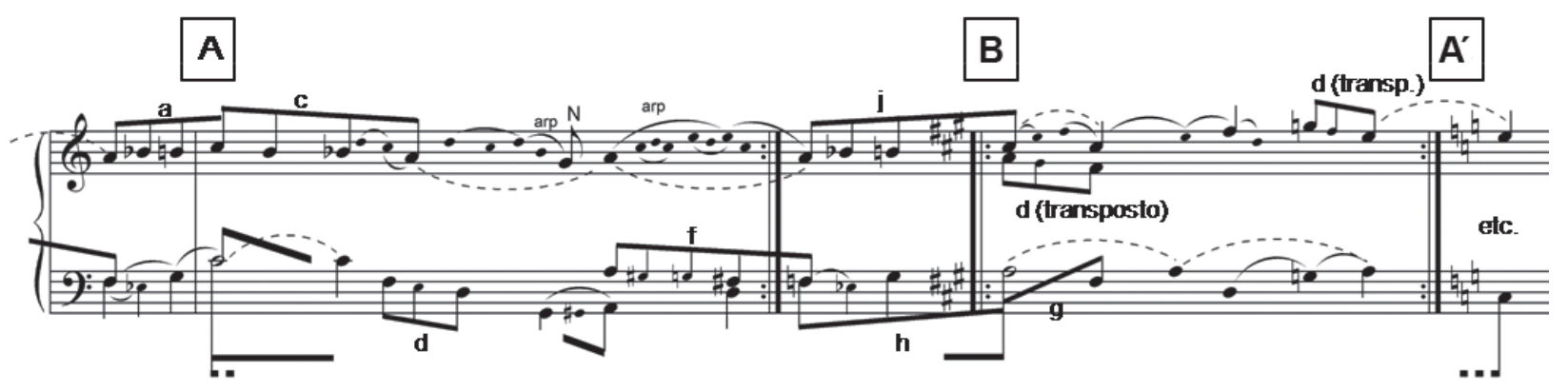

Ex.6 - Something - análise derivativa (primeiro nível intermediário)

partição alternativa do mesmo intervalo ( $1+2$ semitons), a forma $d$, que pode ser considerada uma espécie de versão diatônica da Grundgestalt (e, obviamente, da variante c).

Através de uma operação de expansão por um semitom da linha melódica da forma c é obtida a variante $f$, que, como nos casos anteriores, vincula-se ao respectivo total intervalar (terça maior descendente), representado pela forma $g$. A aplicação de inversão sobre $g$ produz $i$, que suporta a versão diatônica $h$ (alternativamente obtida através de $d$, por intermédio de uma conjunção de operações de expansão, transposição e inversão, como indica o gráfico do Ex.5). Por fim, a forma $h$ serve de base para a variante (quase) cromática $j$, a partir de uma subdivisão assimétrica do total intervalar $(1+1+1+2$ semitons).

Como se observa no Ex.5, as formas derivadas podem ser agrupadas quanto à extensão intervalar (terça menor ou maior) e quanto ao sentido (ascendente ou descendente). Cabe ainda acrescentar que, a despeito do número relativamente elevado de formas resultantes e da complexidade dos processos de variação progressiva acima descritos, observa-se que elas mantêm estreitas ligações de parentesco, não apenas em relação à Grundgestalt, mas também entre si próprias (as setas tracejadas indicam algumas associações redundantes, como espécies de "curtos-circuitos" entre as formas), revelando um quadro de grande coesão (ou de baixa diluição) derivativa. ${ }^{7}$

0 Ex.6 apresenta uma redução analítica inicial (primeiro nível intermediário) de Something, com a indicação das manifestações da Grundgestalt e de suas nove variantes.

Esta análise em primeiro nível enseja algumas observações relevantes, considerando-se a interação das formas abstratas: (1) a frase inicial do canto (forma c) reapresenta a Grundgestalt em movimento retrogradado (a), porém em uma "velocidade" mais lenta; (2) ainda dentro da seção $A$, fica evidente a relação imitativa entre $c$ e $f$, na troca do contexto harmônico (I para VI); (3) na passagem para a 
seção B (na segunda vez do ritornelo) o riff é expandido em um semitom (j), possibilitando a surpreendente modulação para Lá maior. A instigante linha do baixo que suporta essa variante revela um novo significado contrapontístico em relação à sua aparição original, pois os seus pontos de apoio (Fá-Sol-Lá) configuram a versão diatônica expandida da Grundgestalt (h). ${ }^{8}$

No nivel seguinte de redução (Ex.7) desaparecem as menções aos fragmentos melódicos (cromáticos ou diatônicos - as formas $a, c, d, f, h, j$ ), restando apenas as relações intervalares básicas (as diferentes espessuras das hastes informam seus graus distintos de importância estrutural). É interessante perceber neste nível que os encadeamentos harmônicos resumem-se, em cada âmbito tonal (Dó maior e Lá maior), a relações de terça entre fundamentais: I-VI, VI-IV (=VI de Lá)-I, I-VI, VI-I (=VI\# de Dó)-I). Uma outra informação pertinente diz respeito ao sentido intervalar predominante em cada seção: ascendente (formas e e $g$ ) em $A$ (desconsiderando o riff introdutório), e descendente (formas $i$ e b) na seção $\mathrm{B}$, incluindo, neste caso, a retomada do riff, com sua respectiva linha de baixo, em décimas paralelas (uma nova exceção é o intervalo de terça menor descendente forma e - que liga as fundamentais Lá e Fá\#).

Finalmente, a terceira redução confirma a importância do elemento intervalar primordial na estrutura da peça.

\section{Conclusões}

Este estudo demonstra a viabilidade da aplicação de métodos de análise de Grundgestalt/variação progressiva em peças selecionadas do repertório de música popular. Tanto Chovendo na Roseira quanto Something, a despeito das evidentes e inconciliáveis diferenças entre suas realizações (em relação a gênero, estilo, época, nacionalidade e formação de seus compositores), revelam notáveis semelhanças quanto aos processos derivativos desenvolvidos a partir de suas Grundgestalten. Destaquese que, em ambos os casos, a ideia primordial é representada essencialmente por um intervalo melódico característico, cujas potencialidades são exploradas através de variação progressiva, o que gera uma boa quantidade de formas derivadas (como aponta GREEN em seu artigo, relações semelhantes podem ser encontradas nas peças de Ellington por ele analisadas), ainda que estas apresentem
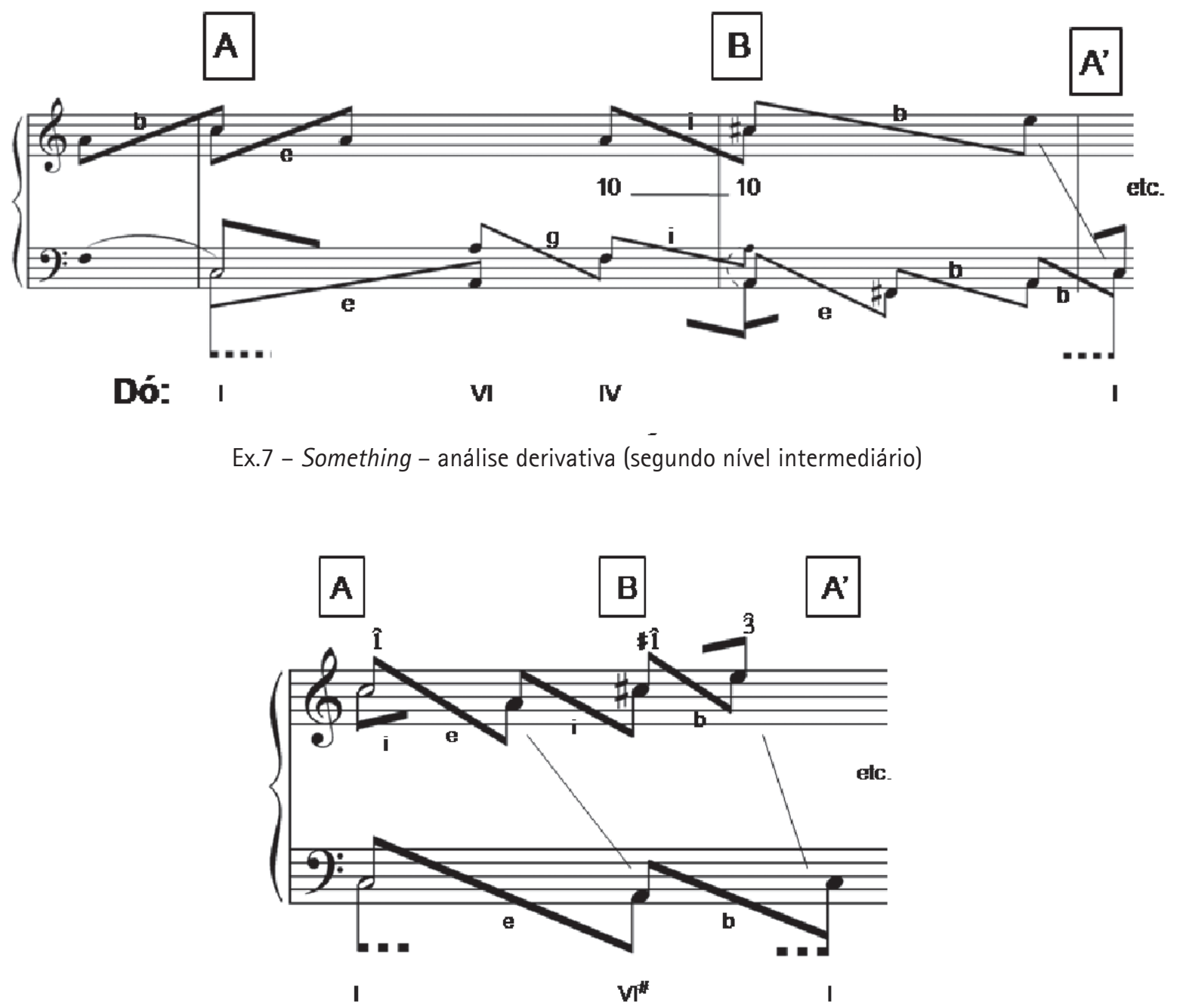

Ex.8 - Something - análise derivativa (terceiro nível intermediário) 
conexões mútuas consideravelmente redundantes. Em oposição, como tem sido constatado nos demais estudos que compõem esta pesquisa, análises derivativas realizadas em peças do repertório musical erudito revelam geralmente Grundgestalten de constituições muito mais complexas, abrangendo simultaneamente, além da configuração intervalar (mais do que um intervalo isolado, como nas canções aqui analisadas). diversos outros aspectos passíveis de abstração, como contorno rítmico, contextos harmônico e métrico etc. Acrescente-se que nesses casos a atuação dos processos derivativos é muito mais abrangente e dispersiva, com a obtenção de um espectro de formas derivadas, em geral, bastante amplo e com baixos graus de redundância. A natureza intervalar do elemento primordial nos casos aqui considerados não parece ser fruto de coincidência, sugerindo uma associação direta com duas características inerentes que compartilham com as demais peças de música popular: duração e complexidade estrutural relativamente menores, se comparadas com obras do repertório erudito (independente de época, estilo e compositor). Em outros termos, a abstração de um intervalo para a formação de um elemento ao mesmo tempo gerador e estruturante pode ser uma estratégia ótima para uma construção orgânica em música popular, uma hipótese cuja validade poderá ser verificada em análises futuras.

Sob outra perspectiva, a menção à palavra "estratégia" na sentença anterior traz de volta a questão do controle do compositor sobre o processo derivativo. A profundidade e a abrangência com que os elementos derivados das Grundgestalten se infiltram nas estruturas de ambas as canções analisadas sugere que dificilmente isso resultaria de planejamento minucioso, ainda que algum tipo de controle possa ter sido parcialmente exercido. ${ }^{9}$ Tal consideração de modo algum é demeritória. Como na situação descrita por Schoenberg, a constatação a posteriori de relações estreitas de coerência e de conexões parentais entre elementos da estrutura de uma peça, mesmo que não planejadas "conscientemente", sugere a existência de uma rara e profunda concepção criativa (ou senso de forma, nos termos schoenberguianos). Na verdade, embora possam ser valiosas para outros tipos de investigação (sob perspectivas musicológica ou cognitiva, p.ex.), informações sobre um maior ou menor (ou sobre a ausência total de) controle sobre os processo derivativos são inteiramente irrelevantes para a análise de Grundgestalt.

\section{Referências}

ALMADA, Carlos de L. Aplicações composicionais de um modelo analítico para variação progressiva e Grundgestalt. Opus, Porto Alegre, vol.18, no 1, p.127-152, jun., 2012a.

Um modelo analítico para variação progressiva e Grundgestalt. In: XXII ENCONTRO ANUAL DA ANPPOM, 2012. João Pessoa. Anais ... João Pessoa: UFRN, 2012b.

. A estrutura derivativa e suas contribuições para a análise e para a composição musical. In: Encontro de Musicologia de Ribeirão Preto, IV, 2012, Ribeirão Preto. Anais... Ribeirão Preto: EDUSP, p.205-214, 2012c.

. Correlações entre estrutura musical e narrativa poética em Carinhoso. Revista Brasileira de Estudos da Canção, Natal, v.1, n.1, 2012d.

. A Ursatz jobiniana: Considerações sobre aplicações da análise schenkeriana em estudos de música popular. In: 3er Congreso Latinoamericano de Formación Académica en la Música Popular. Villa María. Anais ... Villa Maria: UNVM, 2011a. 1 CD-ROM (10 p.).

Derivação temática a partir da Grundgestalt da Sonata para Piano op.1, de Alban Berg. In: II Encontro Internacional de Teoria e Análise Musical. Anais ...São Paulo: UNESP-USP-UNICAMP, 2011b. 1 CD-ROM (11 p.).

A variação progressiva aplicada na geração de ideias temáticas. In: // Simpósio Internacional de Musicologia. Rio de Janeiro: UFRJ, 2011c (no prelo).

Chovendo na roseira de Tom Jobim: Uma abordagem schenkeriana. Per Musi - Revista Acadêmica de Música, Belo Horizonte, n.22, 2010, p.99-106.

BOSS, Jack. Schoenberg's Op. 22 radio talk and developing variation in atonal music. Music Theory Spectrum, v. 14, n.2, 1992, p.125-149.

BURTS, Devon. An application of the grundgestalt concept to the First and Second Sonatas for Clarinet and Piano, Op. 120, no. 1 \& no. 2, by Johannes Brahms. 2004. Dissertação (Mestrado em Música) - University of South Florida.

CARPENTER, Patricia. Grundgestalt as tonal function. Music Theory Spectrum, v.5, 1983, p.15-38.

DUDEQUE, Norton. Music theory and analysis in the writings of Arnold Schoenberg (1874-1951). Aldershot: Ashgate Publishings, 2005.

Variação progressiva como um processo gradual no primeiro movimento do Quarteto A Dissonância,

K. 465, de Mozart. PerMusi - Revista Acadêmica de Música, Belo Horizonte, v.8, 2003, p.41-56. 
EMBRY, Jessica. The role of organicism in the original and revised versions of Brahms's Piano Trio In B Major, Op. 8, Mvt. I: A comparison by means of Grundgestalt analysis. 2007. Dissertação (Mestrado em Música) - University of Massachusetts Amherst.

EPSTEIN, David. Beyond Orpheus: Studies in music structure. Cambridge: The MIT Press, 1980.

FRISCH, Walter. Brahms and the principle of developing variation. Los Angeles: University of California Press, 1984.

GILBERT, Steven E. Gershwin's art of counterpoint. Musical Quaterly, n.70/4, 1984, p.423-56.

GREEN, Edward. "It don't mean a thing if it ain't got that Grundgestalt!"- Ellington from a motivic perspective. Jazz Perspectives, v.2, n.2, 2008, p.215-49.

HAIMO, Ethan. Developing variation and Schoenberg's serial music. Musical Analysis, v.16, n.3, 1997, p.349-65.

MARTINEZ, Alejandro. La forma-oración en obras de la Segunda Escuela de Viena: un lectura desde la morfología de Goethe. Revista del Instituto Superior de Música, Santa Fe, n.12, 2009, p.96-113.

MEYER, Leonard. Style and music. Chicago: The University of Chicago Press, 1989.

RAHN, John. Basic atonal theory. Nova lorque: Longman, 1980.

SCHOENBERG, Arnold. Style and idea: selected writings of Arnold Schoenberg. (Leonard Stein, ed.). Londres: Faber \& Faber, 1984.

\section{Notas}

1 Em relação à primeira, ver ALMADA (2011b; 2011c; 2012a; 2012b; 2012c). Para a segunda pesquisa, ver ALMADA (2010; 2011a; 2012d).

2 Para Organicismo e a influência das descobertas de Darwin sobre a música romântica, ver MEYER (1989, p. 189-96). Para o papel de Goethe na elaboração do conceito de Grundgestalt por Schoenberg, ver BURTS (2004, p. 7-9) e MARTINEZ (2009). Para estudos analíticos e teóricos sobre variação progressiva e Grundgestalt, ver, por exemplo: FRISCH (1984), CARPENTER (1983), EPSTEIN (1989), BOSS (1992), HAIMO (1997), DUDEQUE (2003; 2005), BURTS (2004) e EMBRY (2007).

3 Schoenberg apresentou na Rádio Frankfurt em 1933 uma palestra intitulada "Brahms, o progressivo", que seria tranformada em um ensaio de mesmo título, publicado em 1950 na coletânea Style and Idea (SCHOENBERG, 1984, p.398-441).

4 Como se percebe, são empregados neste exame alguns recursos gráficos e terminológicos originados da análise schenkeriana, devidamente adaptados à presente finalidade. Tal tipo de estratégia tem-se mostrado de grande eficácia em outros trabalhos recentes dentro da pesquisa, já que permite avaliar precisamente os graus de "profundidade" das diferentes relações estabelecidas pela Grundgestalt dentro da estrutura de uma peça.

5 De acordo com a terminologia e a simbologia adotadas pelo modelo analítico que dá suporte a este estudo (e que, por sua vez, é adaptada de RAHN, 1980), o sinal "<...>" indica a presença de uma sequência de eventos (neste caso, apenas um) e os números inseridos representam classes intervalares (em quantidades de semitons), sendo suas direções indicadas pelos sinais "+" (ascendente) e "-" (descendente.

6 Frase que é tocada pelo próprio Harrison na gravação original da canção, que faz parte do álbum Abbey Road (Apple, 1969).

7 Em análises, por assim dizer, mais tradicionais de Grundgestalt, abrangendo repertório musical erudito, observa-se normalmente uma situação contrária, com a produção de formas variantes consideravelmente distintas da fonte original, o que, como já mencionado, atribui-se às maiores extensões territoriais e complexidades estruturais envolvidas. Em outras palavras, é normativo na aplicação de variação progressiva a diluição derivativa e a tendência para afastamento do núcleo motívico referencial.

80 elemento-chave na modulação é o acorde de Sol maior, engenhosamente escolhido por sua notável ambiguidade funcional: atua tanto como $V$ grau em Dó maior quanto como bVII em Lá maior, sendo este último encadeamento (i.e., bVII-I) um dos mais característicos do idioma harmônico do rock.

9 Tal consideração, evidentemente, deve ser também apoiada por conhecimentos externos às estruturas das canções, como o histórico particular de vida dos compositores, suas formações musicais, seus respectivos modus operandi, bem como outros fatores contextuais. A partir dai, é possível especular que, no caso específico de Jobim (um compositor com uma formação musical tradicional e reconhecidamente influenciado por Chopin, Debussy e Villa-Lobos, bem como pela corrente mais sofisticada do jazz dos anos 1950-60), é bastante provável que a manipulação do intervalo de quarta descendente tenha sido em parte controlada, ao menos na perspectiva mais superficial (o desenrolar do motivo principal pelas seções da peça) e, um pouco menos, nas camadas intermediárias imediatamente "abaixo" da superfície (na organização interna da seção contrastante, por exemplo). Contribui ainda para tal conjectura o fato de as relações em Chovendo na Roseira serem consideravelmente mais simples, claras, esquemáticas e em menor número ( $\mathrm{e}$, portanto, de mais fácil "controle") do que aquelas presentes em Something. Por outro lado, Harrison, como um músico de excepcional talento, porém de formação quase exclusivamente intuitiva, dificilmente poderia ter criado sua canção a partir dos desdobramentos da ideia primordial (o solo introdutório da guitarra), na sequência de acontecimentos sugerida pela análise. Isto seria extremamente atípico, considerando sua maneira habitual de compor (ou a de seus parceiros mais prolíferos, Lennon e McCartney, que certamente tomou como modelo). Além disso, percebe-se que algumas das implicações da Grundgestalt são nitidamente resultantes do arranjo (como as "respostas" da linha do baixo), sugerindo uma parcela de contribuição coletiva na composição.

Carlos Almada é Professor Adjunto da Escola de Música da UFRJ, atuando como docente nos níveis de graduação e pósgraduação. É doutor e mestre em Música pela UNIRIO, ambos os cursos com pesquisas voltadas para análises estruturais da Primeira Sinfonia de Câmara op.9, de Arnold Schoenberg. É compositor, com diversas obras apresentadas em edições da Bienal de Música Brasileira Contemporânea, bem como registradas em CDs pela gravadora Ethos Brasil. Atua também na música popular como arranjador, com inúmeros trabalhos gravados recentemente. É pesquisador com vários artigos publicados em periódicos acadêmicos, tendo apresentado comunicações nos quatro últimos congressos da ANPPOM, a partir de suas pesquisas. É autor dos livros Arranjo (Editora da Unicamp, 2001), A estrutura do choro (Da Fonseca, 2006) e Harmonia funcional (Editora da Unicamp, 2009), bem como coautor de uma série de 12 livros sobre música popular brasileira, publicados entre 1998 e 2010 pela editora americana MelBay. 